Prepared in cooperation with the

South Florida Water Management District

\title{
Synthesis of the Hydrogeologic Framework of the Floridan Aquifer System and Delineation of a Major Avon Park Permeable Zone in Central and Southern Florida
}

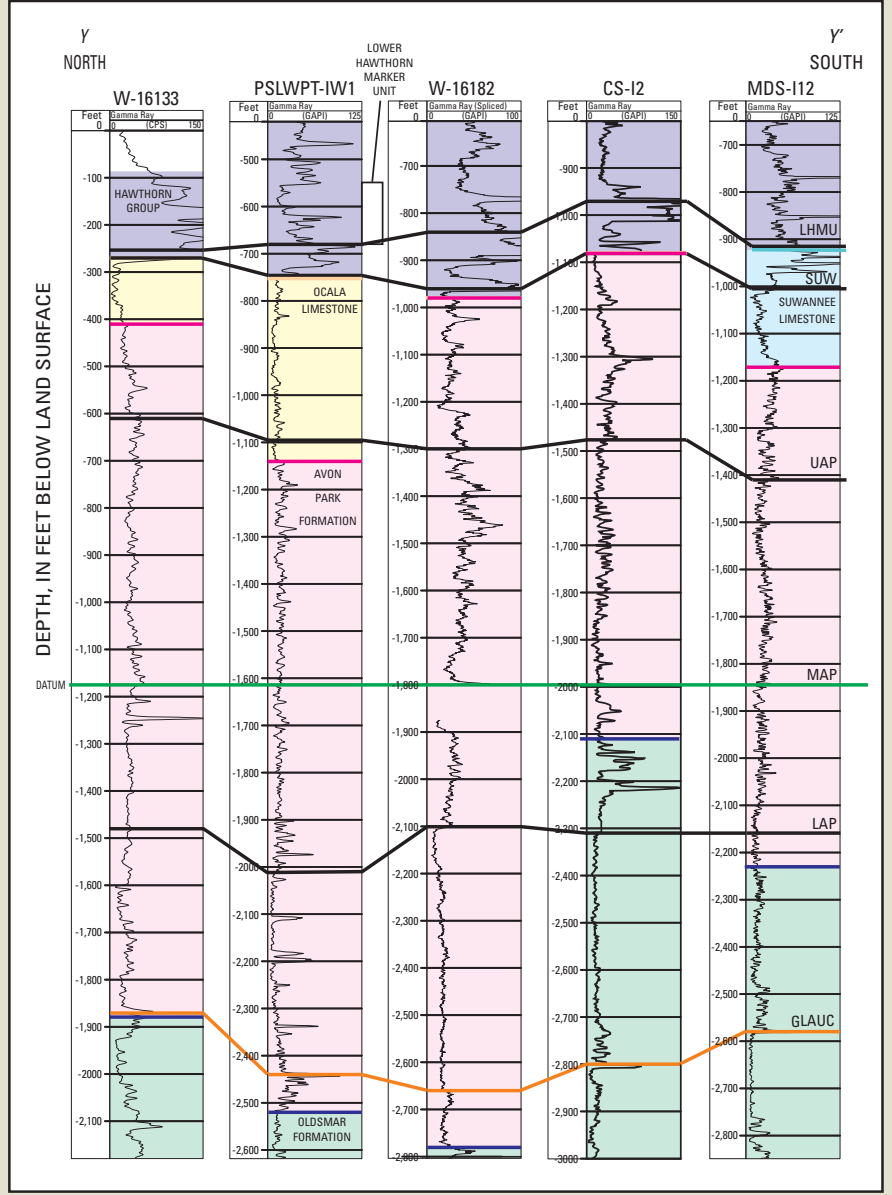

Scientific Investigations Report 2007-5207

U.S. Department of the Interior U.S. Geological Survey

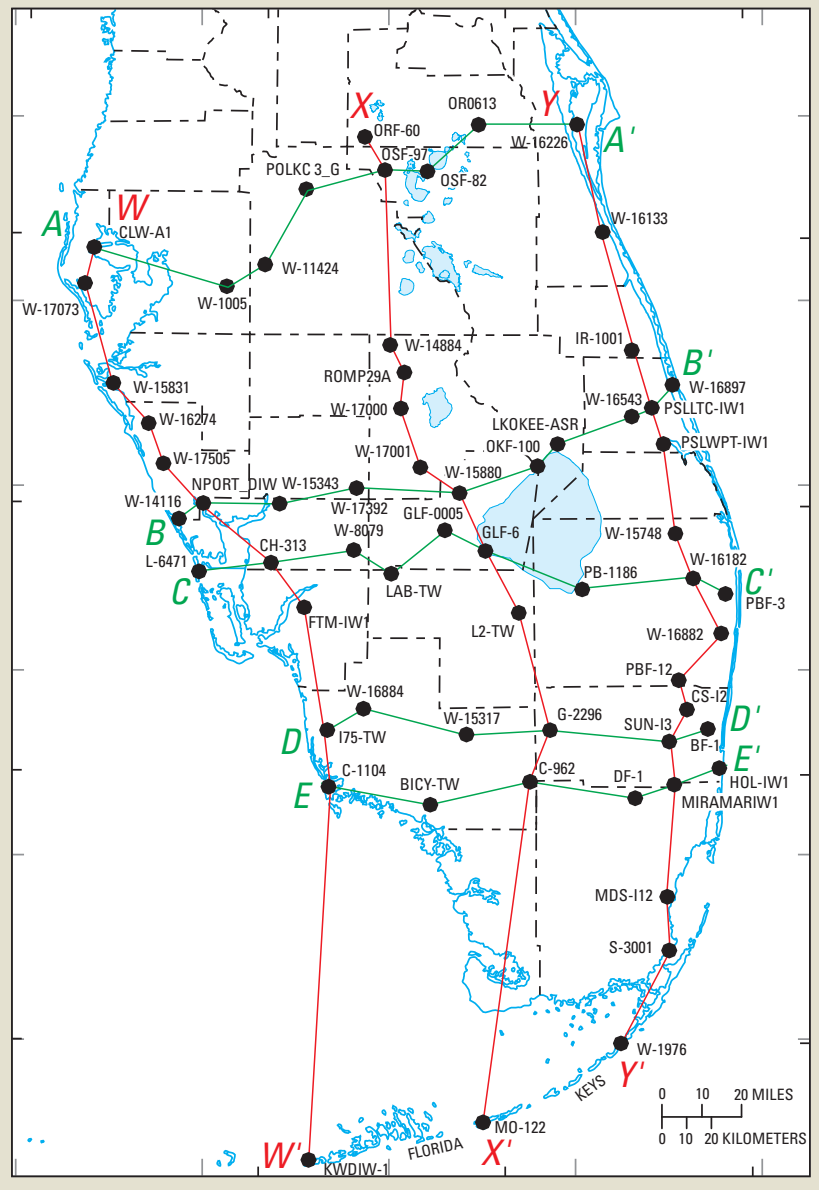

